University of Nebraska - Lincoln

DigitalCommons@University of Nebraska - Lincoln

March 2001

\title{
Genetic and Diurnal Variation in the Juvenile Hormone Titer in a Wing-Polymorphic Cricket: Implications for the Evolution of Life Histories and Dispersal
}

Anthony J. Zera

University of Nebraska - Lincoln, azera1@unl.edu

Gretchen Cisper

University of Nebraska - Lincoln

Follow this and additional works at: https://digitalcommons.unl.edu/bioscizera

Part of the Microbiology Commons

Zera, Anthony J. and Cisper, Gretchen, "Genetic and Diurnal Variation in the Juvenile Hormone Titer in a Wing-Polymorphic Cricket: Implications for the Evolution of Life Histories and Dispersal" (2001). Anthony Zera Publications. 1.

https://digitalcommons.unl.edu/bioscizera/1

This Article is brought to you for free and open access by the Papers in the Biological Sciences at DigitalCommons@University of Nebraska - Lincoln. It has been accepted for inclusion in Anthony Zera Publications by an authorized administrator of DigitalCommons@University of Nebraska - Lincoln. 


\section{Genetic and Diurnal Variation in the Juvenile Hormone Titer in a Wing-Polymorphic Cricket: Implications for the Evolution of Life Histories and Dispersal}

\author{
Anthony J. Zera* \\ Gretchen Cisper \\ School of Biological Sciences, University of Nebraska, \\ Lincoln, Nebraska 68588
}

Accepted 11/13/00

\begin{abstract}
The wing-polymorphic cricket, Gryllus firmus, contains (1) a flight-capable morph $\left(\mathrm{LW}_{\mathrm{f}}\right)$ with long wings and functional flight muscles, (2) a flightless morph with reduced wings and underdeveloped flight muscles (SW), and (3) a flightless morph with histolyzed flight muscles but with fully developed wings $\left(\mathrm{LW}_{\mathrm{h}}\right)$. The $\mathrm{LW}_{\mathrm{f}}$ morph differed genetically from the SW morph and phenotypically from the $\mathrm{LW}_{\mathrm{h}}$ morph in the size of flight muscles, ovarian growth during the first week of adulthood, and the hemolymph titer of juvenile hormone $(\mathrm{JH})$. This is the first study to document that phenotypes that differ genetically in morphological aspects of dispersal capability and in ovarian growth also differ genetically in the titer of a hormone that potentially regulates those traits. The $\mathrm{JH}$ titer rose 9-100-fold during the photophase in the flight-capable $L_{\mathrm{f}}$ morph but did not change significantly during this time in either flightless morph. Prolonged elevation of the in vivo JH titer in flightcapable females, by topical application of a hormone analogue, caused a substantial increase in ovarian growth and histolysis of flight muscles. The short-term, diurnal rise in the JH titer in the dispersing morph may be a mechanism that allows $\mathrm{JH}$ to positively regulate nocturnal flight behavior, while not causing maladaptive histolysis of flight muscles and ovarian growth. This is the first demonstration of naturally occurring, genetically based variation for diurnal change in a hormone titer in any organism.
\end{abstract}

\footnotetext{
*Corresponding author; e-mail: azera@unlserve.unl.edu.
}

Physiological and Biochemical Zoology 74(2):293-306. 2001. 2001 by The University of Chicago. All rights reserved. 1522-2152/2001/7402-0083\$03.00

\section{Introduction}

Juvenile hormone $(\mathrm{JH})$ is an insect hormone that regulates such diverse traits as the synthesis of yolk protein, uptake of this molecule into the developing egg, diapause, flight and reproductive behaviors, and developmental and reproductive features of phase, caste, and dispersal polymorphisms (Rankin 1978; Denlinger 1985; Pener 1985; Rankin et al. 1986; Nijhout 1994, 1999; Trumbo et al. 1995; Wyatt and Davey 1996; Strambi et al. 1997; Zera and Denno 1997). In this study, we investigated the role of $\mathrm{JH}$ in regulating intraspecific variation in and tradeoffs between key life-history and dispersal traits in the wingpolymorphic cricket Gryllus firmus.

The physiological causes of life-history variation and tradeoffs have been an important topic in evolutionary biology for over 6 decades (Fisher 1930; Williams 1966; Stearns 1992; Sinervo 1999). Most research on this topic has focused on energetic aspects, such as the differential allocation of nutrients to egg production versus somatic growth (Ketterson and Nolan 1992, 1999; Zera et al. 1998; Zera and Harshman 2001). Regulatory aspects of life-history physiology remain poorly studied.

There are several reasons to suspect that variation in endocrine regulation might be an important physiological cause of life-history variation and trade-offs. First, classic life-history traits, such as the age at which reproduction begins, are tightly controlled by hormones (Kerkut and Gilbert 1985; Norris 1996; Wyatt and Davey 1996). Hence, variation in these life-history traits might be due to differences in the titers of hormones that regulate their expression. Second, hormones typically affect a number of traits simultaneously. Thus, variable hormone titers might underlie correlations (i.e., trade-offs) between life-history traits (Ketterson and Nolan 1992, 1999; Zera et al. 1998). Few studies have directly measured variation, especially genetically based variation, in the titers of hormones and associations between hormone titers and life-history traits or trade-offs (Ketterson and Nolan 1992, 1999; Zera et al. 1998; Sinervo et al. 2000; Zera and Bottsford 2001).

The endocrine causes of intraspecific variation in dispersal and trade-offs between dispersal and reproduction also are poorly understood, although they have received considerable attention (Southwood 1961; Johnson 1969; Pener 1985; Dingle 1996; Zera and Denno 1997). JH is thought to regulate many aspects of this trade-off (Pener 1985; Rankin et al. 1986; Zera and Denno 1997; Zera et al. 1998). However, few studies have 
directly measured correlations between the JH titer and aspects of dispersal and reproduction (e.g., flight propensity, development of wings and flight muscles, ovarian growth; Rankin and Riddiford 1978; Zera et al. 1989; Zera and Denno 1997).

Dispersal polymorphisms, such as wing and flight-muscle polymorphism, are ideal experimental models to study the endocrine-genetic causes of variable life-history and dispersal traits and trade-offs between traits (Roff 1986; Zera and Denno 1997; Zera et al. 1998; Nijhout 1999). Wing or flight-muscle polymorphic species contain one morph that is capable of flight and one or more flightless morphs with reduced, nonfunctional wings and/or flight muscles. Importantly, flight capability trades off with early reproduction. That is, ovarian growth begins earlier, and fecundity during early adulthood is considerably higher in the flightless morph compared with its flight-capable counterpart (Zera and Denno 1997; Zera et al. 1997, 1998). The regulation of morph-specific reproduction and flight capability by JH has been a topic of research for decades (Southwood 1961; Hardie and Lees 1985; Nijhout 1994, 1999; Zera and Denno 1997). However, only recently have JH titers been directly quantified in adult morphs of any dispersal polymorphic species (Cisper et al. 2000). Information on genetically based differences in the $\mathrm{JH}$ titer, which is especially important for understanding evolutionary aspects of endocrine regulation, is lacking. The main goals of this study were to determine whether morphs of the wing-polymorphic cricket, G. firmus, differ genetically in morphological aspects of flight capability, ovarian growth, and the titer of $\mathrm{JH}$, which potentially regulates these dispersal and reproductive traits. We also manipulated the in vivo $\mathrm{JH}$ titer in wing morphs to assess its role in regulating differences in ovarian growth, flight capability, and the trade-off between these traits.

\section{Material and Methods}

Species, Stocks, Morphs, Rearing Conditions, and Artificial Selection Study

Gryllus firmus, the sand cricket, occurs in the southeastern United States as a long-winged (IW) morph, some of which are capable of flight, or as a short-winged (SW) morph that is obligately flightless (Veazy et al. 1976). Virtually all SW females molt into adults with white, nonfunctional, underdeveloped flight muscles. All LW females have pink, functional, fully developed muscles at or shortly after the adult molt (denoted as $\mathrm{LW}_{\mathrm{f}}$ ), Some $\mathrm{LW}_{\mathrm{f}}$ adults histolyze their flight muscles, thus becoming flightless (denoted $\mathrm{LW}_{\mathrm{h}}$; see Zera et al. 1997). Gryllus firmus used in this study were derived from stocks selected for the LW or SW morph. Full details of the selection study will be reported elsewhere. Briefly, three blocks (independent selection trials), each of which contained a LW-selected (L), a SW-selected (S), and an unselected (C, control) line, were derived from the same generation of a single base population (Fig. 1). During each generation, each selected line was prop-

\section{(A) Design of selection study}

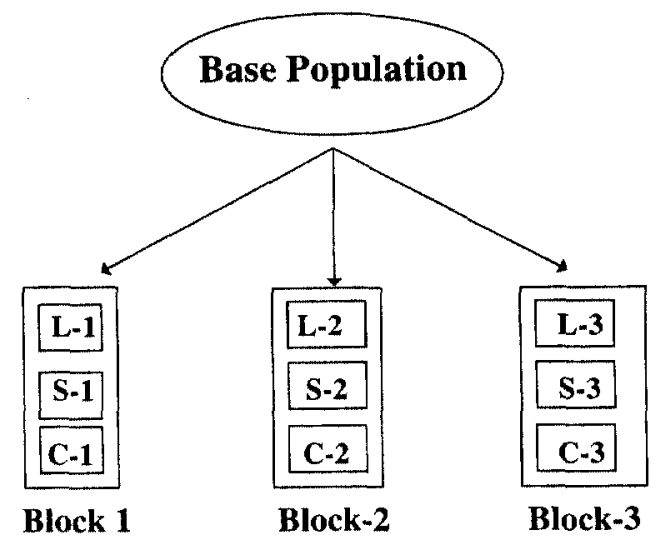

(B) Morph Comparisons

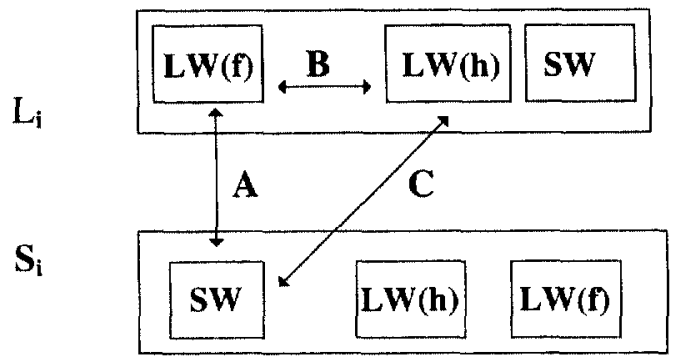

Figure 1. $A$, Design of the artificial selection study on wing morph in Gryllus firmus. $L, S$, and $C$ denote, respectively, lines selected for the long-winged $(L W)$ morph, short-winged $(S W)$ morph, or unselected controls. Block refers to a replicate selection trial (see "Material and Methods" for additional details). $B$, Morph comparisons used in phenotypic $(A, B$, and $C)$ and genetic $(A)$ analyses of flight capability (length of wings and size of flight muscles), ovarian mass, and $\mathrm{JH}$ titer. $L W$, denotes a long-winged morph with large functional flight muscles, while $L W_{h}$ denotes a long-winged morph with small histolyzed flight muscles. The rationale for performing these specific comparisons and statistical analyses are given in the "Material and Methods." Phenotypic analyses were performed on traits measured in individuals, while genetic analyses (comparison $A$ ) were performed on morph means. Note that comparison $A$ is the only single comparison that tests for genetically based differences between $L W_{f}$ and $S W$ morphs. The $L W$, morph from the $S$ lines and the $S W$ morph from the $L$ lines were not studied.

agated by breeding 100-150 males and 100-150 females, all of which had the selected phenotype (e.g., LW in the LW-selected lines). Crickets were raised at $28^{\circ}-30^{\circ} \mathrm{C}$ under a $16 \mathrm{~L}: 8 \mathrm{D}$ photoperiod. All control and selected lines were raised under the same, controlled densities and were fed the same food (see Zera 
and Huang [1999] and Cisper et al. [2000] for details). Females from the eighth (block 3 ) and ninth (blocks 1 and 2) generations of selection were used in this study. By the sixth generation of selection, LW and SW lines differ genetically in wing morph expression (Zera and Huang 1999).

\section{Measurement of JH Titers}

Hemolymph $\mathrm{JH}$ titers were measured in individual females that were 5 or $7 \mathrm{~d}$ old (molt to adult $=$ day 0 ). These days were chosen because ovarian growth is substantially different between $\mathrm{LW}_{\mathrm{f}}$ and $\mathrm{SW}$ or $\mathrm{LW}_{\mathrm{h}}$ morphs at that time (Cisper et al. 2000; see "Results"). Preliminary results indicated that the $\mathrm{JH}$ titer changes considerably during the photophase in a morphspecific manner (see "Results"). Hence, titers were measured within a $2-\mathrm{h}$ period during the morning and evening: 8:0010:00 A.M. or 8:00-10:00 P.M. (lights on at 8:00 A.M. and lights off at 12:00 P.M.). Hemolymph collection and JH extraction were performed as described in Cisper et al. (2000). JH titers were quantified using a well-established radioimmunoassay (RIA) specific for the naturally occurring (10R) enantiomer of $\mathrm{JH}$. Validation of this RIA for quantifying JH levels in crude hemolymph of adult $G$. firmus is reported in Cisper et al. (2000).

\section{Morphological Traits}

Mass of both ovaries, flight-muscle color (white or pink), and wing length (long or short) were recorded for each individual whose $\mathrm{JH}$ titer was determined. Flight-muscle color is strongly correlated with muscle mass and is a reliable indicator of muscle status (Zera et al. 1997; Cisper et al. 2000). No oviposition substrate was provided, and thus, females retained all of their eggs. Ovarian mass is highly correlated with the number of eggs in G. firmus (Roff et al. 1997),

\section{Hormone Application}

Topical application of $10 \mu \mathrm{g}$ of the $\mathrm{JH}$ analogue, methoprene, dissolved in $2 \mu \mathrm{L}$ of acetone, was performed as described previously for Gryllus assimilis (Zera et al. 1998). Methoprene was applied on days 1 and 3 of adulthood (molt to adult = day 0 ). On day 5 , ovarian wet masses and thoracic flight-muscle color (white $=$ nonfunctional; pink $=$ functional) were recorded. Similar measurements were made on crickets that received acetone without hormone (solvent control) or crickets that received neither acetone or hormone (full control).

\section{Analysis of Phenotypic Differences between Morphs}

Phenotypic differences in the $\mathrm{JH}$ titer were analyzed by factorial ANOVA. The dependent variable was hemolymph JH titer measured in an individual cricket. Morph $\left(L W_{f}, L W_{h}, S W\right)$, day (days 5 and 7 of adulthood), time (time of day: morning [A.M.] $=$ 8:00-10:00 A.M., evening [P.M.] = 8:00-10:00 P.M.), and block (three blocks) were the main effects tested. Because preliminary ANOVAs indicated no significant main effect of block or interactions involving block ( $P>0.1$ in all cases), this variable was dropped from subsequent analyses (i.e., data were pooled across blocks). To normalize the JH titer distributions and to equalize their variances, titers were transformed to log ( JH titer +1 ) values. One was added to the JH titer to circumvent the problem of log-transforming zero values (Sokal and Rohlf 1989).

Three separate ANOVAs were performed to test for differences in $\mathrm{JH}$ titers between the following pairs of morphs: $L W_{\mathrm{f}}$ versus $S W, L W_{f}$ versus $L_{h}$, and $L W_{b}$ versus $S W$. These contrasts test the hypotheses, respectively, that the $\mathrm{JH}$ titer varies phenotypically between (1) flight-capable and obligately flightless females with underdeveloped wings and flight muscles, (2) flight-capable and flightless females produced by histolysis of flight muscles during adulthood, and (3) the two types of flightless morphs that are produced by different developmental mechanisms during different life cycle stages. Because these were a priori contrasts, probabilities were not adjusted for experiment-wide error. For reasons described below, morph comparisons were performed using $\mathrm{LW}_{\mathrm{f}}$ and $\mathrm{LW}_{\mathrm{h}}$ individuals from the LW-selected lines and SW individuals from the SW-selected lines (comparisons $A-C$ in Fig. 1).

Variation in ovarian mass was analyzed as percentage body wet mass by the nonparametric Kruskal-Wallis (K-W) test. This test was used, rather than ANCOVA of ovarian mass with body mass as a covariate, because of various statistical problems with the ANCOVA, such as the nonnormal distributions of ovarian mass and the existence of various treatment $\times$ covariate interactions. Because the analysis of ratios is often problematic (Packer and Bordman 1987), a parallel series of K-W tests was performed on unscaled ovarian masses. Results from these two tests were essentially identical, which is expected due to the very high correlation between unscaled and scaled ovarian mass (Spearman correlation $=0.98, n=296$ ). As was the case for ANOVAs of the $\mathrm{JH}$ titer, no significant effect of block was observed in preliminary K-W tests $(P>0.2$ in each test). Thus, this categorical variable was dropped from subsequent tests. Three separate $\mathrm{K}-\mathrm{W}$ tests were performed on the same three pairs of morphs, listed above, that were analyzed for variation in JH titer by ANOVA.

\section{Phenotypic Correlations}

Phenotypic associations between ovarian mass, wing length, flight-muscle phenotype, and $\mathrm{JH}$ titer were estimated using the Spearman correlation. This nonparametric correlation was used because ovarian mass (as percentage body mass) was not normally distributed. Flight-muscle phenotype is a dichotomous trait, as is wing length. Correlations were performed by scoring 
Table 1: Frequency of long-winged females in longwing-selected (L), short-wing-selected (S), and control (C) lines of Gryllus firmus

\begin{tabular}{|c|c|c|c|}
\hline \multirow{2}{*}{$\begin{array}{l}\text { Generation/ } \\
\text { Block }\end{array}$} & \multicolumn{3}{|l|}{ Line Type } \\
\hline & $\mathrm{L}$ & $S$ & $\mathrm{C}$ \\
\hline \multicolumn{4}{|c|}{ Generation $8^{\text {a }}$ : } \\
\hline 1 & $.65(364)$ & $.13(161)$ & $.51(412)$ \\
\hline 2 & $.78(407)$ & $.21(279)$ & $.63(99)$ \\
\hline 3 & $.83(200)$ & $.25(220)$ & $.69(368)$ \\
\hline Mean & $.75 \pm .06$ & $.20 \pm .04$ & $.61 \pm .06$ \\
\hline \multicolumn{4}{|c|}{ Generation 9: } \\
\hline 1 & $.82(197)$ & $.24(152)$ & $.52(116)$ \\
\hline 2 & $.82(197)$ & $.05(80)$ & $.62(102)$ \\
\hline 3 & $.77(110)$ & $.07(108)$ & $\ldots$ \\
\hline Mean & $.80 \pm .02$ & $.12 \pm .07$ & $.57 \pm .07$ \\
\hline
\end{tabular}

Note. Numbers in parentheses are the numbers of females scored for wing morph. The LW morph class consists of two flight-muscle morphs, the frequencies of which are given in the "Results."

"Generation since start of artificial selection on wing morph.

short wings or small muscles as 0 and long wings or fully developed muscles as 1 (Roff et al. 1997). Significance levels for the Spearman correlations were taken from Table $Y$ of Sokal and Rohlf (1969), which are corrected for the estimation of multiple correlations. Correlations were estimated separately on A.M. and P.M. samples because preliminary analyses indicated that associations differed dramatically (i.e., were of opposite sign) between these two times of the day. Correlations were also estimated separately for samples containing $\mathrm{LW}_{\mathrm{f}}$ and $\mathrm{LW}_{\mathrm{h}}$ individuals and for $\mathrm{LW}_{\mathrm{f}}$ and $\mathrm{SW}$ individuals. This was done to determine whether various associations and trade-offs involving the $\mathrm{JH}$ titer were the same for morphs that result from flight-muscle variation produced in adults $\left(\mathrm{LW}_{\mathrm{f}}\right.$ and $\left.L W_{h}\right)$ versus the juvenile stage ( $\mathrm{LW}_{\mathrm{f}}$ and SW).

\section{Genetic Analyses of Dispersal Capability, IH Titer, and Ovarian Mass}

Logic of Morph Sampling. The main goal of this study was to test the hypothesis that morphs of $G$. firmus that differ genetically in morphological aspects of flight capability (i.e., presence of functional wings and flight muscles) also differ genetically in $\mathrm{JH}$ titer and ovarian mass. This hypothesis was tested by comparing the $\mathrm{JH}$ titer and ovarian mass between the $\mathrm{LW}_{\mathrm{f}}$ morph from the $L W$-selected lines and the SW morph from the SW-selected lines (cf. Fig. $1 A$ ). The $L_{W}$ morph is the only morph that has fully developed wings and flight muscles and is capable of flight. The SW morph is the major flightless morph in the selected lines and is the only morph that is known to differ genetically from the $L W_{f}$ morph in flight capability (see below and "Results"). By contrast, it is unknown whether the $L W_{f}$ and the flightless, $L W_{h}$ morphs differ genetically in the presence of functional flight muscles, and this could not be determined with data currently available. While not useful for genetic tests, data were also collected on $\mathrm{JH}$ titer and ovarian mass for the $\mathrm{LW}_{\mathrm{h}}$ morph. This was done because $\mathrm{LW}_{\mathrm{h}}$ and $\mathrm{LW}_{\mathrm{f}}$ individuals could not be distinguished until after they had been bled and dissected to determine flight-muscle status. Endocrine and ovarian data for the $\mathrm{LW}_{\mathrm{h}}$ morph allowed important phenotypic comparisons to be performed between $\mathrm{LW}_{\mathrm{h}}$ and $\mathrm{LW}_{\mathrm{f}}$ or SW morphs (described above; cf. Fig. 1B).

Genetic Tests. To verify that LW and SW morphs differ genetically in the expression of wing length, the (arcsine transformed) frequency of the LW morph was compared between the three $L W$-selected and three $S W$-selected lines by paired $t$ tests. A similar test was done to verify that $L W_{f}$ and $S W$ morphs differ genetically in both wing length and muscle mass (i.e., in flight capability). A consistently higher frequency of the $\mathrm{LW}_{\mathrm{f}}$ morph and a consistently lower frequency of the SW morph in the three LW-selected lines compared with the three SWselected lines is strong evidence that these morphs differ in genetic factors that control the expression of functional wings and flight muscles. Paired $t$-tests were performed, essentially, as described in Zera and Huang (1999). For example, the difference in the mean frequency of the $L W$, morph in a $L W$ selected line and the SW-selected line of the same block was calculated for each block. The mean and SE of these differences were computed to obtain a $t$-statistic with $2 \mathrm{df}$ ( 1 - the number of blocks).

Genetic differences in the $\mathrm{JH}$ titer between $\mathrm{LW}_{f}$-selected and SW-selected morphs was ascertained in an analogous manner by performing paired $t$-tests of mean hormone titers. To avoid pseudoreplication, which would result in tests of genetic differences between selected groups involving more than one data point per selected group (Rose et al. 1996), paired $t$-tests were performed on least squares means of titers averaged over the $2 \mathrm{~d}$ of adulthood or separate $t$-tests were performed on each day of adulthood. Preliminary analyses of the JH titer documented a strong interaction between morph and time due to morph-dependent diurnal variation in the JH titer (see "Results"). Consequently, analyses of genetic differences in the $\mathrm{JH}$ titer between morphs were performed separately on titers obtained in the A.M. and P.M. samples. Data from the same individuals used in the phenotypic analyses described above were used in the genetic analysis (cf. Fig. 1A). However, in the genetic analyses the variates were means of selected groups, while in the phenotypic analyses the variates were values measured in individuals.

A similar approach was taken to test for genetic differences in ovarian mass between $L W_{f}$ and SW morphs, except that $K$ $W$ tests were performed on ovarian mass standardized to body mass. As was the case for the phenotypic analyses, a parallel series of K-W tests was performed using unstandardized ovarian mass. Least squares means could not be computed for per- 

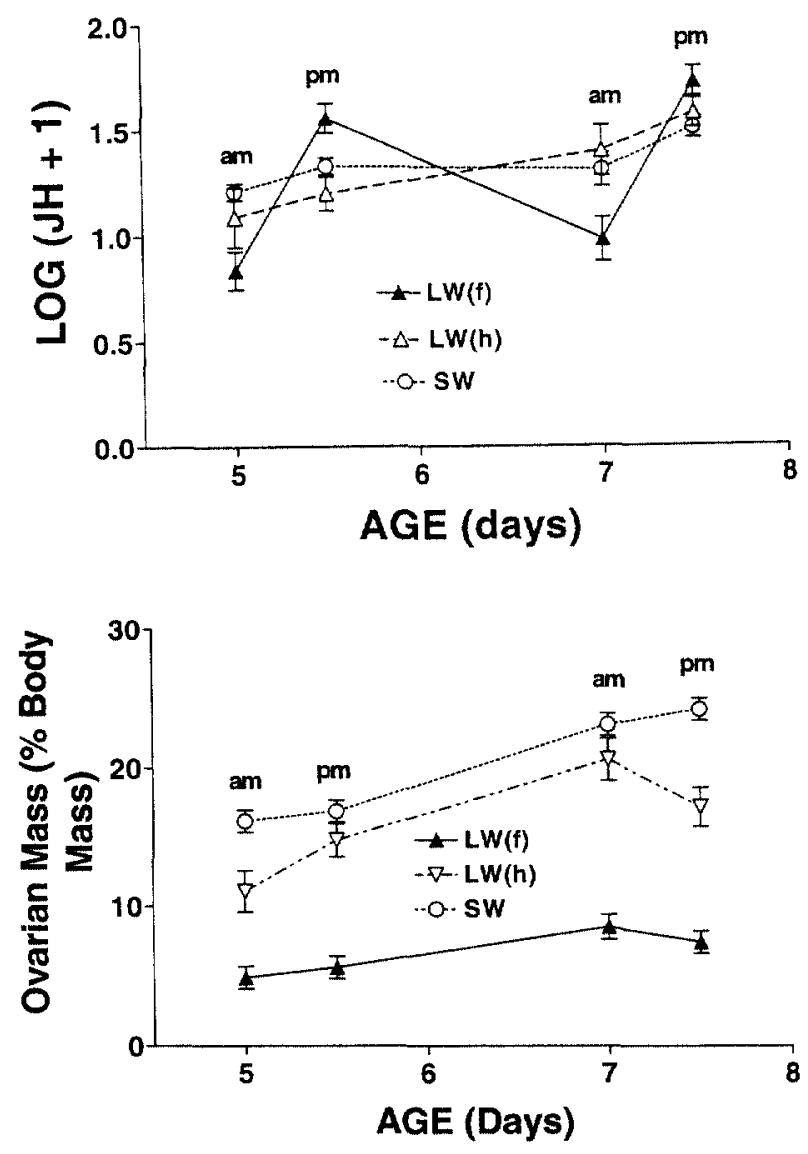

Figure 2. Top panel, mean ( \pm SEM) hemolymph juvenile hormone (JH) titers in the three wing and flight-muscle morphs of Gryllus firmus measured on days 5 and 7 of adulthood (day $0=$ day of molt to adult). Titers were measured between 8:00 A.M. and 10:00 A.M. (morning [A.M.]) and 8:00 P.M.-10:00 P.M. (evening [P.M.]; lights on at 8:00 A.M. and lights off at 12:00 A.M.). $L W_{f}=$ long-winged morph with functional flight muscles; $L W_{n}=$ long-winged morph with histolyzed (degenerated) flight muscles; $S W=$ short-winged morph (with underdeveloped flight muscles). Mean titers are based on data pooled across the selected lines (see Fig. 3 for morph means in individual lines). Bottom panel, as in top panel but mean $( \pm S E M)$ percentage whole-body wet mass due to wet mass of both ovaries. Each ovarian and JH titer mean is based on 26-35 $L W_{f}$ or $S W$ females, or 9-16 $L W_{h}$ females.

centage ovarian masses, thus comparisons between morphs for this trait involved K-W tests performed separately on each of days 5 and 7 of adulthood.

\section{Results}

Genetic Differences between $L W_{f}$ and SW Morphs in Wing Length and Flight Muscles

The frequencies of the LW and SW morphs in the three LWselected and three SW-selected lines are given in Table 1. The grand mean frequency of the LW morph was significantly higher in $\mathrm{LW}$ - versus SW-selected lines during either generation 8 or 9 (paired $t$-tests: generation $8, t_{2}=14.9, P<0.005$; generation $9, t_{2}=14.6, P<0.005$ ). Thus, the LW morph from the LW-selected lines and the SW morph from SW-selected lines differ in genetic factors that control the expression of wing length.

The LW morph consists of two flight-muscle morphs, the flight-capable $L_{\mathrm{f}}$ morph, which has fully developed flight muscles, and the flightless $\mathrm{LW}_{\mathrm{h}}$ morph, which has histolyzed flight muscles (see "Material and Methods"). The frequencies of the $\mathrm{LW}_{\mathrm{f}}$ morph on days 5 and 7 of adulthood in the three LW-selected lines during generation 8 were as follows: day 5 , $0.52(n=20), \quad 0.62 \quad(n=20), \quad 0.72 \quad(n=15), \quad$ mean $=$ $0.62 \pm 0.058 ;$ day $7,0.47(n=46), 0.49(n=45), 0.58(n=$ $10)$, mean $=0.51 \pm 0.029$. The frequency of the $\mathrm{LW}_{\mathrm{h}}$ morph was not determined in the SW-selected lines. However, it cannot be greater than the frequency of the LW morph in those lines (i.e., $<0.25$; Table 1). Thus, the difference in the frequency of the $\mathrm{LW}_{\mathrm{f}}$ morph between the LW-selected and SW-selected lines was assessed by comparing the grand mean frequency of the $\mathrm{LW}_{\mathrm{f}}$ morph from the three $\mathrm{LW}$-selected lines with the grand mean frequency of the LW morph from the three SW-selected lines. Although this is a conservative test, highly significant differences in the grand mean frequencies were observed on either day $5\left(t_{2}=11.9, P<0.01\right)$ or day $7\left(t_{2}=16.5, P<\right.$ 0.005 ; paired $t$-tests; all day 5 and day 7 means were arcsine transformed). Thus, the $\mathrm{LW}_{\mathrm{f}}$ morph from the LW-selected lines and the SW morph from the SW-selected lines differ genetically in both functional wings and functional flight muscles, both of which are necessary for flight.

\section{Phenotypic Differences in the JH Titer between Wing Morphs}

Diurnal Variation. The flight-capable $L W_{\mathrm{f}}$ morph differed substantially from the two flightless morphs in the extent to which the hemolymph $\mathrm{JH}$ titer changed during the day (Figs. 2, 3). Each flightless morph exhibited a relatively constant logtransformed $\mathrm{JH}$ titer during the day ( $<15 \%$ change; Fig. 2 ). The JH titer did not differ significantly between the A.M. and P.M. samples for the $L W_{\mathrm{h}}$ morph on either day $5\left(F_{1,23}=\right.$ $0.50, P>0.4)$ or day $7\left(F_{1,17}=1.65, P>0.15\right)$. No, or marginal, statistically significant diurnal variation in the $\mathrm{JH}$ titer was observed for the SW morph on day $5\left(F_{1,68}=3.49, P=0.07\right)$ and day $7\left(F_{1,38}=4.47, P=0.04\right)$. By contrast, the $\mathrm{JH}$ titer exhibited a cyclic diurnal pattern of variation in the $L W_{f}$ morph, with the log-transformed titer increasing $76 \%-85 \%$ from the morning to the evening. Differences in the $\mathrm{JH}$ titer in the $\mathrm{LW}_{\mathrm{f}}$ morph between A.M. and P.M. samples were highly significant on both day 5 (ANOVA: $\left.F_{1,64}=36.5, P<0.0005\right)$ and day $7\left(F_{1,54}=\right.$ 34.3, $P<0.0005$; Fig. 2).

Diurnal change in the untransformed hemolymph $\mathrm{JH}$ titer of individual $\mathrm{LW}_{\mathrm{f}}$ and $\mathrm{SW}$ crickets from one of the three blocks 

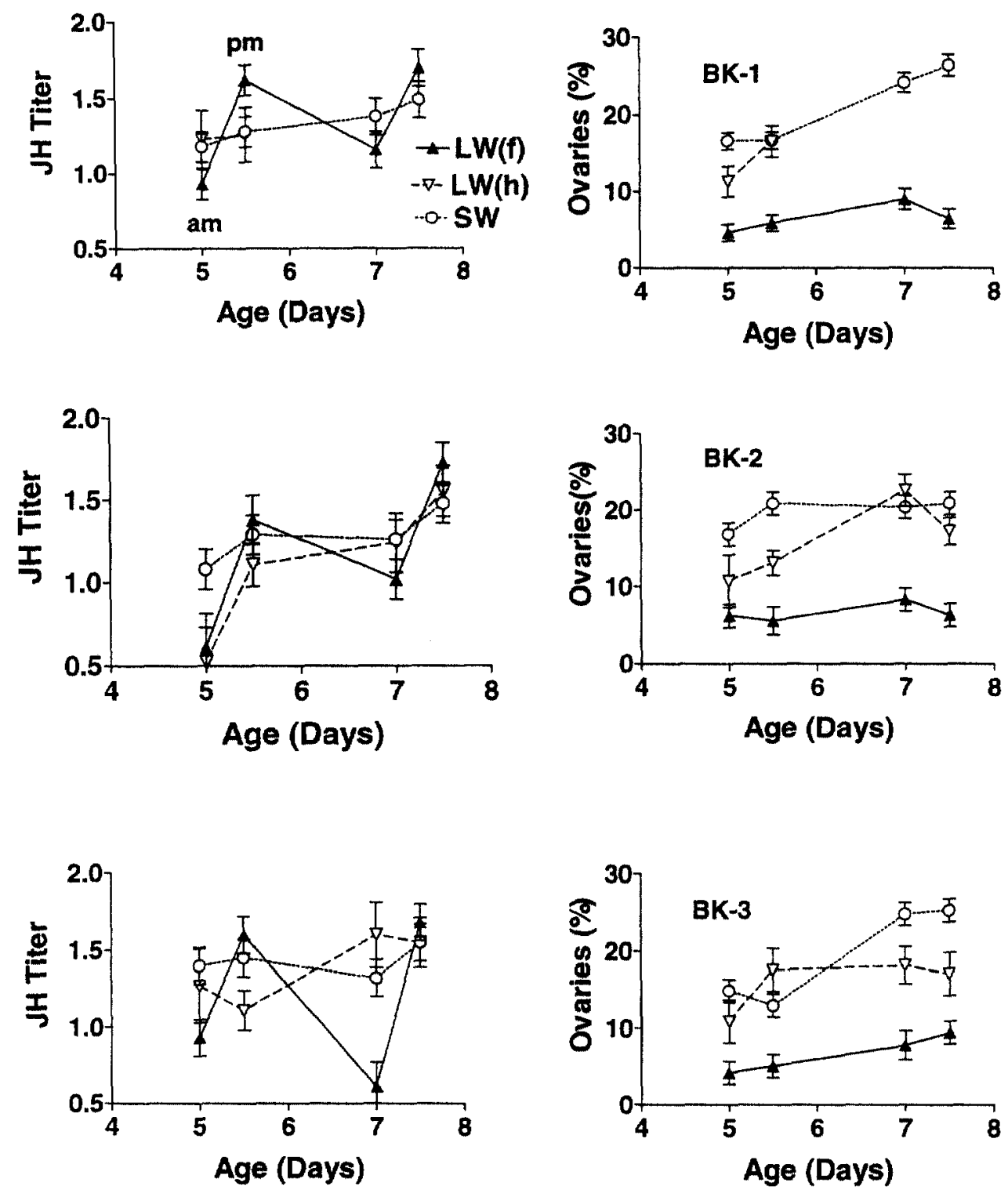

Figure 3. Mean JH titer ( $\log [\mathrm{JH}$ titer +1$]$; see "Material and Methods") and mean ovarian mass (as percentage body wet mass), in $L W_{f}, L W_{h}$, and $S W$ morphs from selected lines of the three blocks. Morph designations are defined in Figure 2 . In each block, $L W_{f}$ and $L W_{h}$ morphs were derived from the $L W$-selected line, while the $S W$ morph was derived from the $S W$-selected line (see Fig. 1). Means were based on $10-15 L W W_{f}$ or $S W$ morphs, except for $L W_{f}$ in block 2 , day 5, P.M. $(n=7)$ and $L W_{f}$ in block 3 , day 7 , A.M. $(n=6)$. Means for $L W_{h}$ individuals were based on 3-10 individuals, except for block 2, day 5, A.M. $(n=2)$.

is illustrated in Figure 4. In the $\mathrm{LW}_{\mathrm{f}}$ morph, the median $\mathrm{JH}$ titer increased ninefold to 100 -fold from the morning to the evening on both days 5 and 7 . By contrast, the median $\mathrm{JH}$ titer increased less than twofold in the SW morph on either day (Fig. 4). Like the SW morph, the JH titer in the flightless $\mathrm{LW}_{\mathrm{h}}$ morph increased only one- to threefold on either day (see Fig. 4 legend for median titers). Similar diurnal variation in the $\mathrm{JH}$ titer in individual crickets was observed for the three morphs from selected lines of the other two blocks (data not shown).

IH Titer during the A.M. or P.M. The JH titer was significantly lower in the flight capable ( $\mathrm{LW}_{\mathrm{f}}$ ) morph compared with either of the two flightless morphs ( $\mathrm{LW}_{\mathrm{h}}$ or $\mathrm{SW}$ ) during the beginning of the photophase (A.M. samples; Figs. 2, 3; Table 2). By con- 


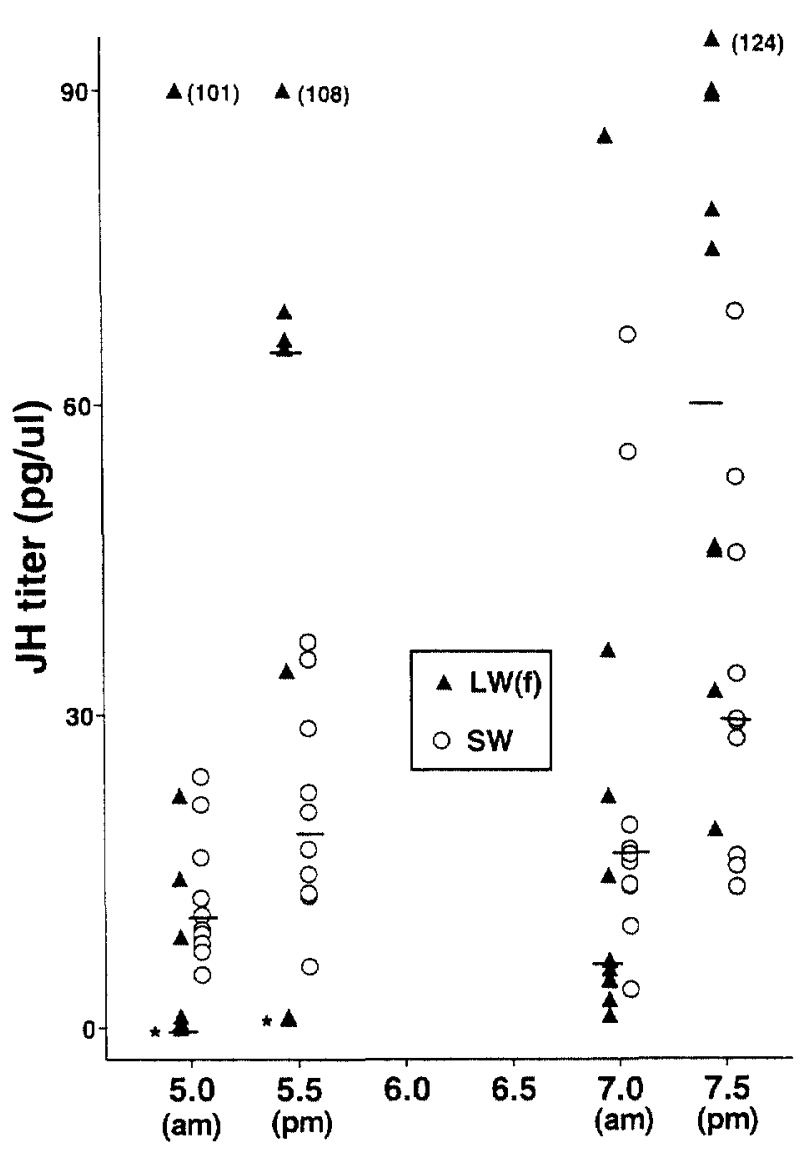

Age (days) and time of day

Figure 4. A.M. and P.M. untransformed $\mathrm{JH}$ titers in individual $L W_{f}$ and SW Gryllus firmus. Lines mark median values. Asterisk indicates that the adjacent symbol represents five (day 5) or two (day 5.5 [day 5 , p.M.]) identical values. For clarity, individual titers in $L W_{k}$ females are not included in this figure. Median values for the JH titer in this morph were as follows: day 5, A.M. $=3.2,(n=2)$; day 5, P.M. $=10.1$, $(n=9)$; day 7, A.M. $=22.4,(n=5)$; day 7, P.M. $=34.5,(n=7)$. Symbols and morph designations are the same as those in Figure 2.

trast, in the P.M. samples, the JH titer was significantly higher in the flight-capable $L W_{f}$ morph compared with either flightless morph (Figs. 2, 3). JH titers did not differ significantly between the two types of flightless morph in either the A.M. or P.M. samples (Table 2), and no significant morph $\times$ day interaction was observed in any comparison (Table 2 ).

\section{Genetic Differences in the JH Titer between LW-Selected and SW-Selected Morphs}

The grand mean JH titer (pooled across days 5 and 7) was significantly lower in the $\mathrm{LW}_{\mathrm{f}}$ versus the SW morph in the A.M. sample $\left(t_{2}=11.67, P=0.007\right)$ and was significantly higher in the P.M. sample ( $t_{2}=4.80, P<0.05$; Fig. 5$)$. Thus, these two morphs differ genetically in the JH titer both early and late in the photophase. Genetic differences in the JH titer between the $\mathrm{LW}_{\mathrm{f}}$ and SW morphs also are evident in the consistent titer differences between morphs from selected lines of the same block for each of the three blocks (Fig. 3). The JH titer was significantly lower in the $\mathrm{LW}_{\mathrm{I}}$ morph compared with the SW morph for the A.M. samples in block $1\left(F_{1,46}=5.17, P<0.03\right)$, block $2\left(F_{1,36}=5.76, P<0.025\right)$, and block $3\left(F_{1,32}=12.5\right.$, $P<0.001)$. For the P.M. samples, the JH titer was significantly higher in the $\mathrm{LW}_{\mathrm{f}}$ compared with the SW morph in block 1 $\left(F_{1,43}=9.8, P<0.005\right)$, but titers were equivalent in these two morphs in block $2\left(F_{1,33}=1.7, P=0.2\right)$ and in block 3 $\left(F_{1,36}=1.8, P=0.19\right)$.

The grand mean JH titer in the $\mathrm{LW}_{\mathrm{f}}$ morph increased significantly from the A.M. to the P.M. $\left(t_{2}=13.08, P=0.006\right)$ but did not change between these two times of day in the SW morph $\left(t_{2}=1.99, P=0.19\right.$; paired $t$-tests of least squares $\mathrm{JH}$ titers averaged over days 5 and 7; Fig. 5). Thus, the $\mathrm{LW}_{\mathrm{f}}$ and SW morphs differed genetically in diurnal fluctuation of the $\mathrm{JH}$ titer. The consistent cycling of the JH titer in the $\mathrm{LW}_{\mathrm{f}}$ morph, but not in the SW morph in each of the three blocks (Fig. 3), also indicates that these morphs differ genetically in diurnal fluctuation in the $\mathrm{JH}$ titer. These different temporal patterns resulted in a significant morph $\times$ time interaction in ANOVAs of $\mathrm{JH}$ titers in $\mathrm{LW}_{\mathrm{f}}$ and $\mathrm{SW}$ morphs in each of the three blocks (block 1, $F_{1,91}=14.2, P<0.0005 ;$ block 2, $F_{1,69}=7.0, P=$ 0.01 ; block $\left.3, F_{1,68}=14.5, P<0.0005\right)$.

\section{Phenotypic and Genetic Differences between Morphs in Ovarian Mass}

In contrast to the JH titer, no significant phenotypic difference was observed in ovarian mass between the morning and evening samples $(P>0.05$ in each of six K-W tests; $P>0.25$ in five of six tests; Fig. 2). However, on each day, at each time of day, the $\mathrm{LW}_{\mathrm{f}}$ morph had significantly smaller percentage ovarian mass compared with either the SW or $\mathrm{LW}_{\mathrm{h}}$ morph $(P<0.005$ for each of eight $\mathrm{K}-\mathrm{W}$ tests). Percentage body mass due to ovaries also differed phenotypically between the two flightless morphs (SW and $\mathrm{LW}_{\mathrm{h}}$ ) in the day 5 A.M. (K-W test: $H_{1}=$ $8.7, P<0.05)$ and day 7 P.M. samples $\left(H_{1}=10.55, P<0.005\right)$ but not in the day 5 P.M. $\left(H_{1}=0.69, P>0.1\right)$ or day 7 A.M. samples $\left(H_{1}=2.35, P>0.1\right)$. However, as was the case for the $\mathrm{JH}$ titer, phenotypic differences in ovarian mass between the two flightless morphs were much smaller than differences between the flight-capable $\mathrm{LW}_{\mathrm{f}}$ morph and either flightless morph (Fig. 2),

The SW morph also exhibited a genetically based elevation in ovarian mass compared with the $\mathrm{LW}_{\mathrm{f}}$ morph (Fig. 5). Grand mean ovarian mass (as percentage body mass) was significantly higher for the $\mathrm{LW}_{\mathrm{f}}$ morph compared with the SW morph for each time of day on each of days 5 and 7 of adulthood 
Table 2: Analysis of phenotypic variation in the $\mathrm{JH}$ titer in Gryllus firmus by factorial ANOVA in the morning (A.M.) and evening (P.M.)

\begin{tabular}{lccc}
\hline \multirow{2}{*}{$\begin{array}{l}\text { Time of Dayl } \\
\text { Source of Variation }\end{array}$} & \multicolumn{3}{l}{ Morphs Compared } \\
\cline { 2 - 4 } L.M.: & & & \\
Morph & $20.3^{* * *}$ & $6.1^{* *}$ & $.06 \mathrm{NS}$ \\
& $(4.008)$ & $(1.579)$ & $(.007)$ \\
Day & $2.3 \mathrm{NS}$ & $2.8 \mathrm{NS}$ & $4.9^{*}$ \\
& $(.450)$ & $(.707)$ & $(.614)$ \\
Error & $122 \mathrm{df}$ & $75 \mathrm{df}$ & $79 \mathrm{df}$ \\
& $(.197)$ & $(.257)$ & $(.124)$ \\
P.M.: & $12 . \mathrm{LW}^{* * *}$ & $7.20^{* *}$ & \\
Morph & $(1.43)$ & $(1.03)$ & $(.015)$ \\
& $7.32^{* *}$ & $8.60^{* *}$ & $20.6^{* *}$ \\
Day & $(.82)$ & $(1.23)$ & $(1.43)$ \\
& $122 \mathrm{df}$ & $83 \mathrm{df}$ & $87 \mathrm{df}$ \\
Error & $(.112)$ & $(.143)$ & $(.069)$ \\
\hline
\end{tabular}

Note. Values above parentheses are $F$-ratios or degrees of freedom, while values within parentheses are mean squares. Block was removed from the ANOVA because no significant main effect or interactions involving this variable were observed (see "Material and Methods"); all morph $\times$ day interactions were nonsignificant $(P>0.1)$. Morph and day each had $1 \mathrm{df} . \mathrm{LW}_{\mathrm{f}}=$ longwinged morph with functional flight muscles; $\mathrm{LW}_{\mathrm{h}}=$ long-winged morph with histolyzed flight muscles; $S W=$ short-winged morph with underdeveloped flight muscles; NS $=$ not significant $(P>0.1) ; \mathrm{df}=$ degrees of freedom.

*** $P<0.005$.

** $P<0.025$

$* P<0.05$.

( $H_{1}=3.86, P<0.05$ for each of the four $\mathrm{K}-\mathrm{W}$ tests). On each of days 5 and 7 , neither the $L_{W}$ or the SW morph showed a significant change in mean ovarian mass between the A.M. and P.M. samples $(P>0.25$ in each $\mathrm{K}-\mathrm{W}$ test $)$. Thus, in contrast to the $\mathrm{JH}$ titer, there is no evidence for genetic differences between these morphs in temporal change in ovarian mass.

\section{Hormone Manipulation}

Topical application of methoprene reduced flight-muscle mass and increased ovarian mass in $\mathrm{LW}_{\mathrm{f}}$ females from one of the selected lines, converting all treated $L W_{\mathrm{f}}$ females into $\mathrm{LW}_{\mathrm{h}} \mathrm{fe}$ males by day 5 (Table 3 ). In this experiment, solvent and full controls did not differ significantly in morph proportions $\left(\chi^{2}\right.$ test, $P>0.1$ ). Nor did the $\mathrm{LW}_{\mathrm{f}}$ or $\mathrm{LW}_{\mathrm{h}}$ morphs differ in either ovarian or flight-muscle mass between the two types of controls ( $P>0.1$ in each $t$-test). Thus, data from these two control groups were combined and tested against data for the hormonetreatment group. The proportion of $\mathrm{LW}_{\mathrm{h}}$ individuals in the hormone-treated group was significantly greater than that in the pooled control group $\left(\chi_{1}^{2}=22.2, P<0.001\right)$. LWh individuals produced by hormone manipulation were very similar to control $\mathrm{LW}_{\mathrm{h}}$ females in mean ovarian mass ( $t$-test; $t_{23}=0.79$, $P=0.4$ ) and only differed slightly (ca. $15 \%$ ), but significantly $\left(t_{23}=2.40, P=0.025\right)$, in flight-muscle mass.

\section{Correlations}

Phenotypic correlations between ovarian mass, flight-muscle mass, and $\mathrm{JH}$ titer were similar, whether computed on $\mathrm{LW}_{\mathrm{f}}$ and $\mathrm{SW}$ females or on $\mathrm{LW}_{\mathrm{f}}$ and $\mathrm{LW}_{\mathrm{h}}$ females (Table 4). Ovarian mass exhibited a highly significant negative correlation (tradeoff) with flight-muscle mass that was statistically indistinguishable between the A.M. and P.M. samples. By contrast, the JH titer was positively correlated with ovarian mass and negatively correlated with flight-muscle mass in the morning samples, while correlations in the evening were of opposite sign. The reversal in the sign of these correlations was due to the increase in the $\mathrm{JH}$ titer in the $\mathrm{LW}_{\mathrm{f}}$ morph in P.M. versus A.M. samples coupled with no significant change in ovarian or flight -muscle mass (Fig. 6). This is most apparent in scatterplots of mean JH titer and mean ovarian mass (Fig. 7 ).

\section{Discussion}

\section{Diumal Variation in the JH Titer}

An unexpected and intriguing finding of this study was the strong morph-dependent diurnal variation in the $\mathrm{JH}$ titer in Gryllus firmus (Figs. 2-5). On each of $2 \mathrm{~d}$ of adulthood, the $\mathrm{JH}$ titer increased substantially (nine- to 100 -fold) over a 12 $\mathrm{h}$ period in $\mathrm{LW}_{\mathrm{f}}$ females, while no significant change in the $\mathrm{JH}$ titer occurred during this time in either flightless morph ( $\mathrm{LW}_{\mathrm{h}}$ or SW; Fig. 4). This reversed the direction of phenotypic and genetic differences in the $\mathrm{JH}$ titer between the flightless and flight-capable morphs during the beginning and latter parts of the photophase (Figs. 2, 3, 5).

To our knowledge, only two reports of diurnal variation in the JH titer has been published (Walker and Denlinger 1980; Ramaswamy et al. 2000). The very low hemolymph JH concentration during many life-cycle stages has typically required pooling blood samples obtained from many individuals over a prolonged period of the light cycle (e.g., as in Zera et al. 1989). Pooling of samples would tend to obscure any existing diurnal $\mathrm{JH}$ titer variation. Thus, the limited number of reports on temporal fluctuations in the JH titer may be a consequence of the lack of investigation of this phenomenon rather than the rarity of diurnal variation itself. Diurnal or circadian variation has been reported for many hormone titers in both vertebrates and insects (Kerkut and Gilbert 1985; Pener 1985; Nelson 1994; Norris 1996). However, the morph-dependent diurnal variation in the JH titer in G. firmus (Figs. 2-5) is the first case of a complex (multitrait) polymorphism in which naturally occurring morphs, castes, or phases differ either genetically or phenotypically in the temporal pattern of hormone titer fluctuation. 

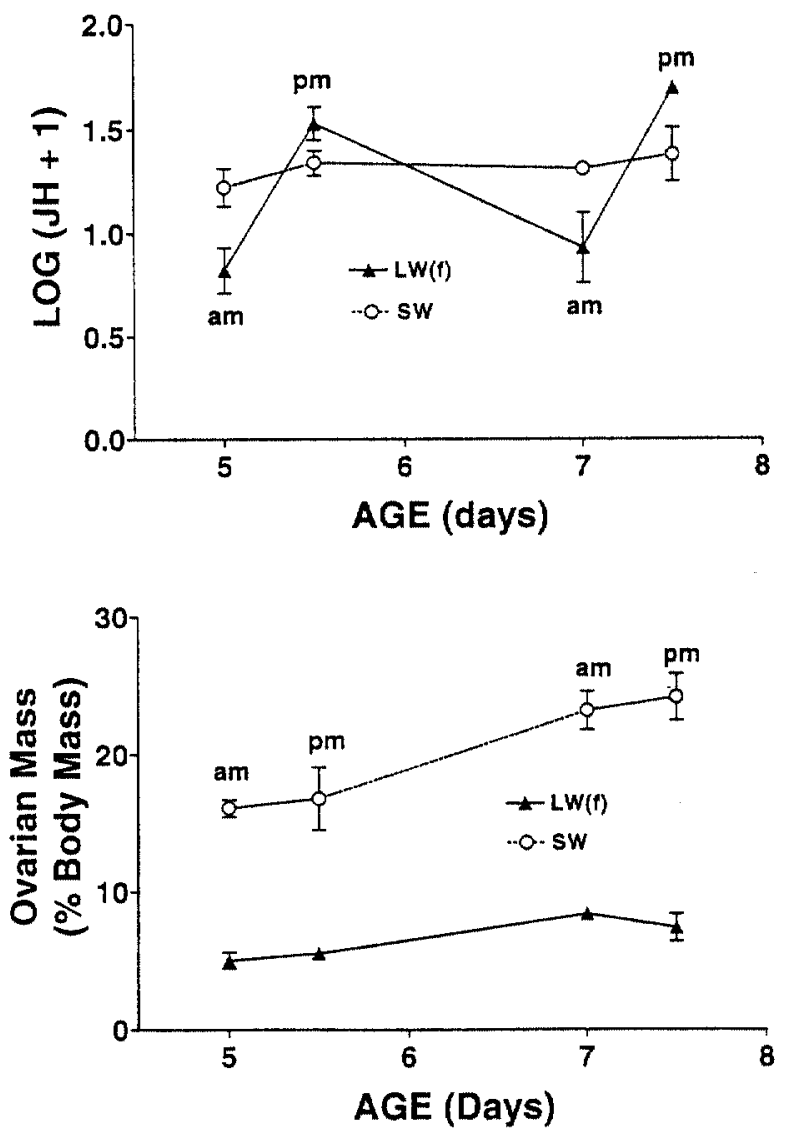

Figure 5. Grand mean JH titers or percentage ovarian masses for $L W_{f}$ and $S W$ genotypes. Bars represent SEs. Each grand mean is based on the three mean values presented in Figure 3. Symbols and morph designations are the same as those in Figure 2.

A key question raised by this study is the functional significance of diurnal change in the JH titer in the flight-capable morph but not in the flightless morphs. We hypothesize that the elevated $\mathrm{JH}$ titer regulates the expression of some as yet unidentified trait related to flight in the $\mathrm{LW}_{\mathrm{f}}$ morph during the late photophase-early scotophase (i.e., dusk-early evening in the field). The diurnal fluctuation in the $\mathrm{JH}$ titer also might be required in the $\mathrm{LW}_{f}$ morph to avoid a prolonged elevation of the $\mathrm{JH}$ titer, which would have adverse effects on flight capability by causing histolysis of flight muscles and ovarian growth. By contrast, a continuously elevated $\mathrm{JH}$ titer in the flightless morph likely regulates the earlier onset and faster ovarian growth that is characteristic of that morph.

A number of lines of evidence support the hypothesis described in the preceeding paragraph. Experimental elevation of the JH titer by topical application of hormone or hormone analogues increased long-duration flight in three phylogenetically distant insect species (Rankin et al. 1986). Moreover, artificial selection for a delay in the onset of long-duration flight in the insect migrant, Oncopeltus fasciatus, resulted in a correlated delay in the rise in the adult $\mathrm{JH}$ titer (Rankin and Riddiford 1978). These studies collectively suggest that an elevated $\mathrm{JH}$ titer regulates long-duration, migratory flight in insects. Thus, it is conceivable that this hormone might play an analogous role in regulating dispersal flight (i.e., shorterdistance, nonmigratory flight) in G. firmus. Gryllus firmus fly in the field (Walker 1986), and two congeners, Gryllus assimilis and Gryllus rubens, are capable of continuous flight of greater than $6 \mathrm{~h}$ in the laboratory (Zera and Rankin 1989; Zera et al. 1999). Many insects, including species of Gryllus, fly only during certain hours of the day or night (Johnson 1969; Walker 1986). For example, the congener Gryllus integer was collected at lights in the field almost exclusively during the first few hours after sunset (Cade 1979). Hence, if JH induces nocturnal, dispersal flight in $G$. firmus, a high JH titer might only be required during a portion of the 24 -h daily cycle. Trumbo et al. (1995) reported that an insect behavior can be regulated by a rapid rise in the $\mathrm{JH}$ titer over several hours. Topical application of $\mathrm{JH}$ or the $\mathrm{JH}$ analogue, methoprene, caused degeneration of flight muscles in several cricket species, including $G$. firmus (Table 3; Pener 1985; Tanaka 1994; Zera et al. 1998). Thus, the JH titer cannot be elevated for a prolonged period of time in these insects without causing loss of flight capability. Finally, when $\mathrm{LW}_{\mathrm{f}}$ adults lost flight ability by histolysis of flight muscles (i.e., were transformed into $\mathrm{LW}_{\mathrm{h}}$ ), the diurnal fluctuation in the $\mathrm{JH}$ titer was also abolished (Figs. 2, 3). In G. firmus, a cyclic $\mathrm{IH}$ titer is clearly correlated with flight capability.

The proximate mechanisms regulating the differences among the morphs in the temporal fluctuation of the JH titer must involve morph-specific activation of hormone biosynthesis and/ or degradation. In the $\mathrm{LW}_{\mathrm{f}}$ morph, activities of the $\mathrm{JH}$ degrading enzymes, JH esterase and $\mathrm{JH}$ epoxide hydrolase, do not differ between the A.M. and P.M. (A. J. Zera, unpublished data). Thus, the rise in the $\mathrm{JH}$ titer in the $\mathrm{LW}_{\mathrm{f}}$ morph most likely occurs by a rapid, morph-specific increase in JH biosynthesis, rather than a decrease in $\mathrm{JH}$ degradation. Recent measurements in one pair of LW-selected and SW-selected lines have shown that, by 4:00 A.M. of days 6 and 8 , the JH titer in the $\mathrm{LW}_{\mathrm{f}}$ morph had dropped to levels as low as those measured at 8:00 A.M. of days 5 and 7 (A. J. Zera, unpublished data). This not only suggests that the temporal fluctuation in the $\mathrm{JH}$ titer in the $\mathrm{LW}_{\mathrm{f}}$ morph is circadian but also indicates that there is a rapid decrease in the $\mathrm{JH}$ titer during a $6-8$-h period. This decrease in the $\mathrm{JH}$ titer likely involves a rapid, morph-specific activation of $\mathrm{JH}$ degradation, sequestration, or excretion.

\section{JH Titer and the Endocrine Regulation of Life Histories}

The endocrine causes of life-history variation and trade-offs is an important but poorly studied topic in life-history physiology (Ketterson and Nolan 1992, 1999; Zera et al. 1998; Zera and 
Table 3: Effect of the juvenile hormone analogue, methoprene, on flight-muscle histolysis and ovarian growth in Gryllus firmus

\begin{tabular}{lrcc}
\hline Morph & Number & Ovarian Mass & Flight-Muscle Mass \\
\hline Control: & & & \\
$\quad \mathrm{LW}_{\mathrm{f}}$ & 25 & $5.6 \pm .6$ & $13.3 \pm .5$ \\
$\mathrm{LW}_{\mathrm{h}}$ & 8 & $12.0 \pm .9$ & $8.3 \pm .3$ \\
Hormone treated: & & & \\
$\mathrm{LW}_{\mathrm{f}}$ & 0 & $\ldots$ & $\ldots$ \\
$\mathrm{LW}_{\mathrm{h}}$ & 17 & $10.5 \pm 1.2$ & $9.8 \pm .4$ \\
\hline
\end{tabular}

Note. Number values represent the number of $\mathrm{LW}_{\mathrm{f}}$ females with large flight muscles and small ovaries or $\mathrm{LW}_{\mathrm{h}}$ females with small, histolyzed flight muscles and large ovaries on day 5 of adulthood; methoprene had been applied on days 1 and 3 of adulthood to LW fernales. Ovarian mass and flight-muscle mass values represent the mean ( \pm SEM) masses of both ovaries (as percentage whole-body wet mass) or thoracic muscles (dorsolongitudinal and dorsoventral muscles, as percentage whole-body wet mass).

Harshman 2001). Before this study, information on the endocrine basis of life-history variation has come from a few behavioral studies of vertebrates in which phenotypic differences in the titers of hormones, such as testosterone, have been documented between individuals that differ in behaviors important to reproductive success (Moore 1986; Marler and Moore 1988; Ketterson and Nolan 1992, 1999; Sinervo et al. 2000). Results of hormone manipulation have buttressed the argument that these correlations represent causal relationships (Marler and Moore 1988; Ketterson and Nolan 1992, 1999).

This study is the first to document that naturally occurring, genetically based variation in the titer of a hormone is correlated with a key physiological component of early fecundity (ovarian growth). However, the functional significance of this correlation in G. firmus is not firmly established. The uncertainty results from the diurnal fluctuation in the $\mathrm{JH}$ titer in the $\mathrm{LW}_{\mathrm{f}}$ morph but not the SW morph, which caused the sign of the correlation between the $\mathrm{JH}$ titer and ovarian mass to change from positive in the A.M. samples to negative in the P.M. samples (Figs. 6, 7; Table 4). Results of $\mathrm{JH}$ titer manipulation in this study (Table 3) and other studies (Pener 1985; Tanaka 1994; Zera et al. 1998), together with a large body of information on JH endocrinology (Kerkut and Gilbert 1985; Nijhout 1994), all strongly support the notion that $\mathrm{JH}$ positively affects ovarian growth in insects in general and in G. firmus in particular. Thus, we tentatively conclude that the positive correlation between the $\mathrm{JH}$ titer and ovarian mass in the A.M. samples reflects the functional relationship between these two traits, while the negative correlation in the P.M. samples represents a spurious, nonfunctional association.

If JH positively affects ovarian growth, how can $\mathrm{LW}_{\mathrm{f}}$ females, which have the highest $\mathrm{JH}$ titer of the three morphs in the evening (Figs. 2, 3), also have the smallest ovaries of the three morphs? One possibility is that the $\mathrm{JH}$ titer might be elevated

Table 4: Spearman phenotypic correlations between the juvenile hormone titer, ovarian mass, and flight-muscle phenotype in Gryllus firmus measured in the morning (A.M.) and evening (P.M.)

\begin{tabular}{|c|c|c|c|c|}
\hline \multirow[b]{3}{*}{ First Variable } & \multicolumn{4}{|l|}{ Second Variables } \\
\hline & \multicolumn{2}{|c|}{$\mathrm{LW}_{\mathrm{f}}$ and SW Morphs } & \multicolumn{2}{|c|}{$\mathrm{LW}_{\mathrm{f}}$ and $\mathrm{LW}_{\mathrm{h}}$ Morphs } \\
\hline & Ovarian Mass & Flight Muscle & Ovarian Mass & Flight Muscle \\
\hline $\begin{array}{l}\text { JH titer } \\
\text { Flight muscle }^{\mathrm{a}}\end{array}$ & $\begin{array}{r}.37^{* *}\left(-.23^{*}\right) \\
-.80^{* *}\left(-.78^{* *}\right) \\
\end{array}$ & $-.36^{* *}\left(.43^{* *}\right)$ & $\begin{array}{r}.27^{*}(-.14 \mathrm{NS}) \\
-.55^{* *}\left(-.64^{* *}\right) \\
\end{array}$ & $-.31^{*}\left(.42^{* *}\right)$ \\
\hline \multicolumn{5}{|c|}{$\begin{array}{l}\text { Note. } L W_{f}=\text { long-winged morph with fully developed flight muscles; } S W=\text { short-winged morph with } \\
\text { underdeveloped flight muscles; } L W_{h}=\text { long-winged morph with histolyzed flight muscles. Correlations of A.M. } \\
\text { samples are outside parentheses, while P.M. correlations are inside. } N=126 \text { for the } L W_{f} \text { and } S W \text { sample; } \\
N=84 \text { for the } L W_{\mathrm{f}} \text { and } L W_{\mathrm{h}} \text { sample; NS = nonsignificant. Probabilities were corrected for estimates of multiple } \\
\text { correlations from the same sample using Table } Y \text { of Sokal and Rohlf (1969). } \\
\text { "In the sample of } L W_{\mathrm{f}} \text { and SW females, long wings is perfectly correlated with fully developed flight muscles } \\
\text { (see "Material and Methods," and Zera et al. [1997] for additional background on morphs). Thus, this correlation } \\
\text { also measures the correlation between ovarian mass and wing length. } \\
* P<0.05 \text {. } \\
* * P<0.01 \text {. }\end{array}$} \\
\hline
\end{tabular}



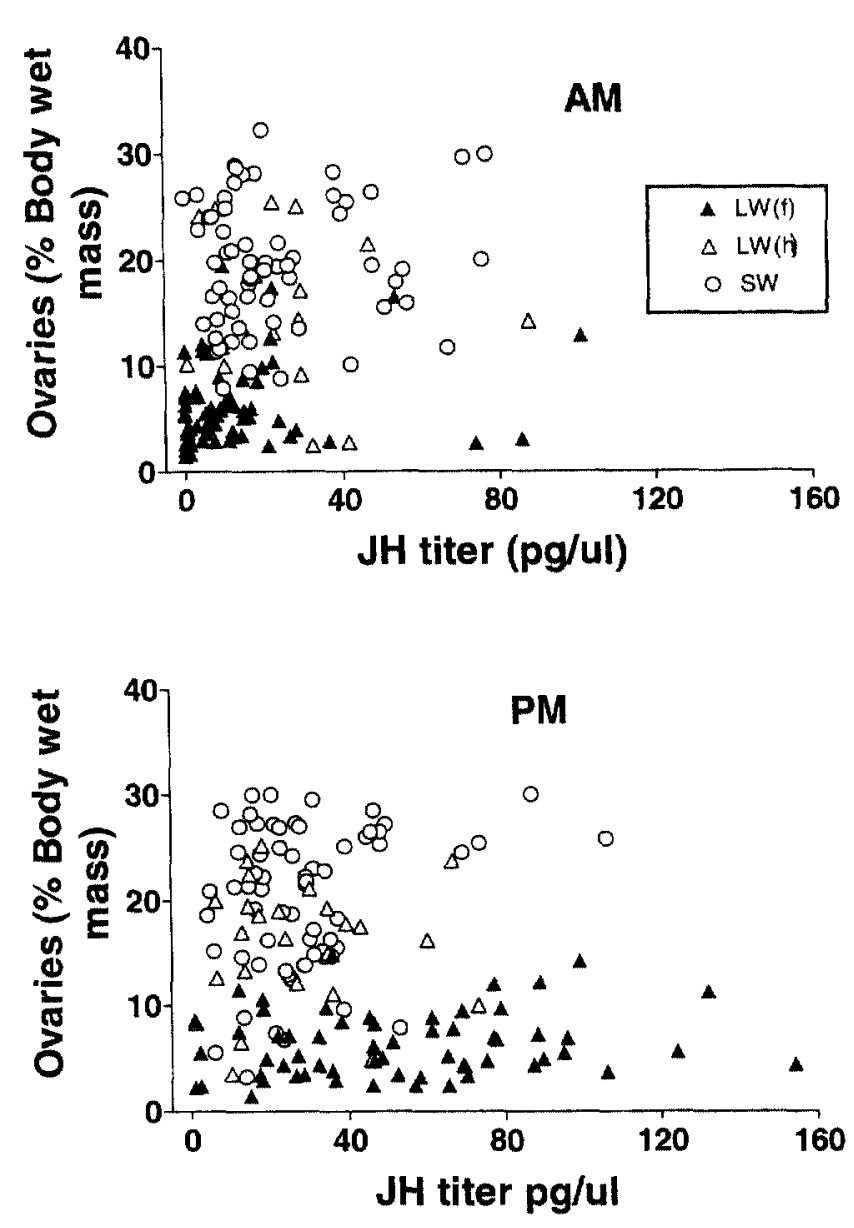

Figure 6. Scatterplots of untransformed $\mathrm{JH}$ titers and percentage body mass due to both ovaries for individual $L W_{f}, L W_{h}$, and $S W$ females of Gryllus firmus measured early (A.M.) or late (P.M.) in the photophase. Symbols and morph designations are the same as those in Figure 2.

for an insufficient period of time to elicit ovarian growth (by 4:00 A.M. the JH titer has returned to the low level observed in the previous morning; A. Zera, unpublished data; see above). Alternatively, $\mathrm{JH}$ antagonists might be produced, titers of other required hormones might be reduced, or $\mathrm{JH}$ receptors in the ovaries and flight muscles might be reduced in $\mathrm{LW}_{\mathrm{f}}$ females during the period of time when the JH titer is elevated. These results clearly show that the endocrine regulation of life-history traits can be more complex than variation in the titer of a single hormone regulating variation in a life-history component such as ovarian growth (Zera 1999).

\section{$J H$ and the Regulation of Dispersal Polymorphism}

Results obtained in this study bear on two central issues in dispersal polymorphism: (1) the regulation of morph-specific reproduction and (2) the regulation of the trade-off between ovarian growth and flight-muscle maintenance. For many decades, an elevated $\mathrm{JH}$ titer has been thought to be a key factor controlling the enhanced reproduction of the flightless morph in wing and flight-muscle polymorphism (Southwood 1961; Wigglesworth 1961; Hardie and Lees 1985; Pener 1985; Nijhout 1994, 1999; Zera and Denno 1997; Zera et al. 1998; Zera 1999). However, only recently has the $\mathrm{JH}$ titer been compared between adult wing or flight-muscle morphs (Cisper et al. 2000). This previous study of $G$. firmus was done before there was knowledge of the morph-dependent temporal fluctuation in the $\mathrm{JH}$ titer in this species, and titers were only measured during a portion of the photophase. Results of the $\mathrm{JH}$ manipulation experiment (Table 3 ), in combination with the in vivo titer measurements (Figs. 2,3,5), clearly implicate variation in the $\mathrm{IH}$ titer as a cause of the difference in ovarian growth between the morphs. However, as discussed above, these studies also show that other factors must be involved. The difference in
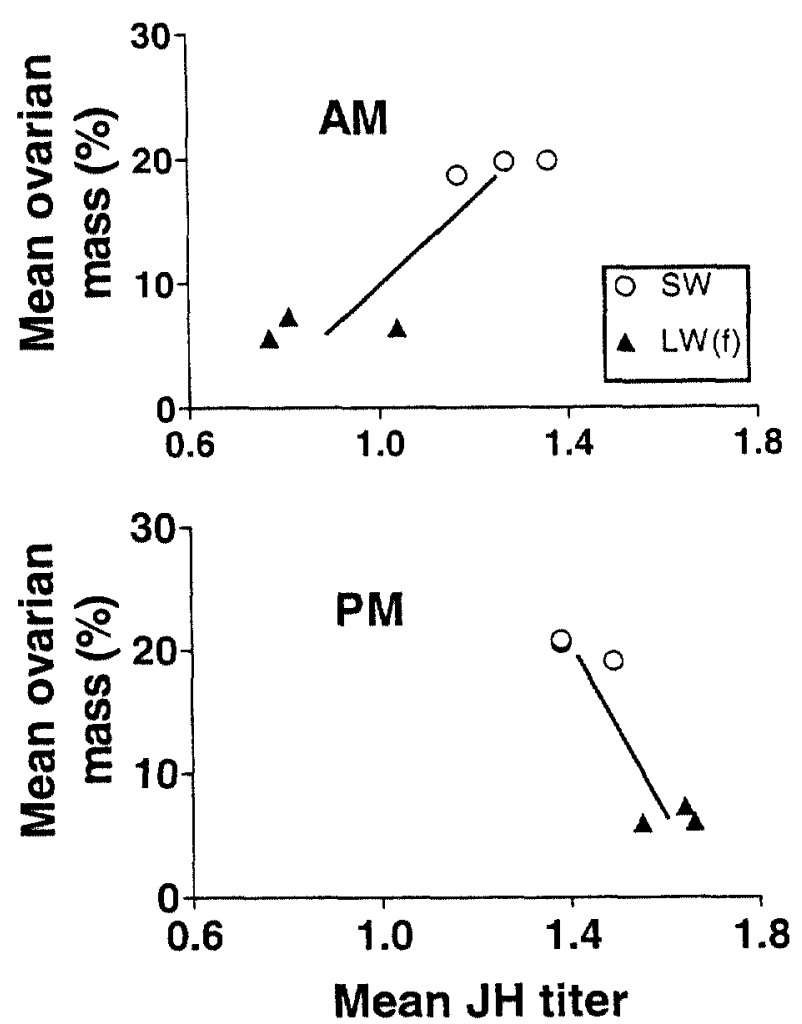

Figure 7. Scatterplots of mean JH titers ( $\log [\mathrm{JH}$ titer +1$]$; see "Material and Methods") and mean ovarian masses for the three $L W_{f}$ and three $S W$ genotypes of Gryllus firmus. Symbols are the same as in Figure 6. Lines are results of linear regression included to emphasize the change in the sign of correlations between A.M. and P.M. samples. Each mean $\mathrm{JH}$ titer and ovarian mass is the least squares mean of values obtained on days 5 and 7 of adulthood. 
ovarian growth between $\mathrm{LW}_{\mathrm{f}}$ and $\mathrm{SW}$ morphs of $\mathrm{G}$. firmus is not exclusively the result of a consistently elevated $\mathrm{JH}$ titer in the flightless morph and a consistently reduced $\mathrm{JH}$ titer in the flight-capable morph, as postulated by the classic JH-morph reproduction hypothesis (Zera and Denno 1997).

Histolysis of flight muscles occurs commonly in reproductive females of many insect species and is thought to be largely responsible for the elevated reproductive output of flightless females (Johnson 1969; Pener 1985; Dingle 1996; Zera and Denno 1997; Zera et al. 1997, 1998). For decades, JH has been postulated to be the main regulator of this trade-off, with a high hemolymph $\mathrm{JH}$ titer enhancing ovarian growth and promoting muscle histolysis and a low JH titer promoting the opposite effects (Johnson 1969; Harrison 1980; Pener 1985; Zera and Denno 1997). All previous discussion of this topic has been based on the results of experimental manipulation of the JH titer (Pener 1985; Tanaka 1994; Zera and Denno 1997). This study is the first to directly test this hypothesis by measuring the in vivo JH titer in LW morphs of G. firmus that differ in both muscle histolysis and ovarian growth ( LW $_{\mathrm{f}}$ and $L_{\mathrm{h}}$ morphs; Figs. 2, 3, 6; Table 4). Results of this test are not definitive; the JH titer in the flight-capable $\mathrm{LW}_{\mathrm{f}}$ morph is either higher or lower than in the flightless $\mathrm{LW}_{\mathrm{h}}$ morph, depending on the time of day (i.e., photophase). The JH titer is likely involved in the regulation of the trade-off between flight-muscle retention and ovarian growth in the $\mathrm{LW}_{\mathrm{f}}$ and $\mathrm{LW}_{\mathrm{h}}$ morphs, but others factors must also be involved.

\section{Implications for Models of Complex Polymorphism}

Models of JH-mediated caste, morph, or phase specialization often postulate that the $\mathrm{JH}$ titer above or below some threshold plays an important role in regulating the expression of alternate suites of coadapted traits (Hardie and Lees 1985; Zera and Tiebel 1989; Nijhout 1994, 1999; Zera and Denno 1997; Zera et al. 1998). Results of this study indicate that it may be necessary to expand these models to incorporate morph-specific temporal fluctuation in hormone titers as an important aspect of the endocrine regulation of morph specialization. The ecdysteroid titer and activity of two JH-degrading enzymes did not vary during the day in a morph-specific manner in $G$. firmus (A. J. Zera, unpublished data). Thus, the morph-specific temporal variation in the $\mathrm{JH}$ titer in $G$. firmus might be limited to one or a few endocrine traits. On the other hand, diurnal variation is known for a wide variety of important dispersal and reproductive traits that differ between morphs or castes of various complex polymorphisms (e.g., flight, oviposition, and various behaviors involved in courtship and mate attraction; Johnson 1969; Saunders 1982; Pener 1985; Walker 1986; Strambi et al. 1997). Thus, endocrine studies of complex polymorphisms need to take into account the possibility that important regulatory differences between morphs may have a strong diurnal component.

\section{Acknowledgments}

Research reported here was supported by grant IBN 9507388 from the National Science Foundation.

\section{Literature Cited}

Cade B. 1979. Field cricket dispersal flights measured by crickets landing at lights. Tex J Sci 31:125-130.

Cisper G., A.J. Zera, and D. Borst. 2000. The endocrine regulation of wing polymorphism: juvenile hormone titer and morph-specific reproduction in the cricket, Gryllus firmus. J Insect Physiol 46:585-596.

Denlinger D.L. 1985. Hormonal control of diapause. Pp. 353-412 in G.A. Kerkut and L.I. Gilbert, eds. Comprehensive Insect Physiology, Biochemistry and Pharmacology. Vol. 8. Pergamon, Oxford.

Dingle H. 1996. Migration: the Biology of Life on the Move. Oxford University Press, Oxford.

Fisher R.A. 1930. The Genetical Theory of Natural Selection. Dover, New York.

Hardie J. and A.D. Lees. 1985. Endocrine control of polymorphism and polyphenism. Pp. 441-490 in G.A. Kerkut and L.I. Gilbert, eds. Comprehensive Insect Physiology, Biochemistry and Pharmacology. Vol. 8. Pergamon, New York.

Harrison R.G. 1980. Dispersal polymorphisms in insects. Annu Rev Ecol Syst 11:95-118.

Johnson C.G. 1969. Migration and Dispersal of Insects by Flight. Methuen, London.

Kerkut G.A. and L.I. Gilbert, eds. 1985. Comprehensive Insect Physiology, Biochemistry and Pharmacology. Vols. 7, 8. Pergamon, New York.

Ketterson E.D. and V. Nolan, Jr. 1992. Hormones and life histories: an integrative approach. Am Nat 140(suppl.):S33-S62.

1999. Adaptation, exaptation, and constraint. Am Nat 154(suppl.):S4-S25.

Marler C.A. and M.C. Moore. 1988. Evolutionary costs of aggression revealed by testosterone manipulations in free-living lizards. Behav Ecol Sociobiol 23:21-26.

Moore M.C. 1986. Elevated testosterone levels during nonbreeding season territoriality in a fall-breeding lizard, Sceloporus jarrovi. J Comp Physiol 158:159-163.

Nelson R. 1994. An Introduction to Behavioral Endocrinology. Sinauer, Sunderland, Mass.

Nijhout H.F. 1994. Insect Hormones. Princeton University Press, Princeton, N.J.

1999. Control mechanisms of polyphenic development in insects. BioScience 49;181-192.

Norris D. 1996. Vertebrate Endocrinology. Lea \& Fabigin, Philadelphia.

Packard G. and T.J. Bordman. 1987. The misuse of ratios to scale physiological data that vary allometrically with body size. Pp. 216-236 in M.E. Feder, A.F. Bennett, W.W. Burg- 
gren, and R.B. Huey, eds. New Directions in Ecological Physiology. Cambridge University Press, Cambridge.

Pener M.P. 1985. Hormonal effects on flight and migration. Pp. 491-550 in G. Kerkut and L.I. Gilbert, eds. Comprehensive Insect Physiology, Biochemistry and Pharmacology. Vol. 8. Pergamon, New York.

Ramaswamy S.B., S. Shu, and A. Srinivasan. 2000. Role of juvenile hormone esterase in mating stimulated egg development in the moth Heliothis virescens. Insect Biochem Mol Biol 30:785-792.

Rankin M.A. 1978. Hormonal control of insect migratory behavior. Pp. 5-32 in H. Dingle, ed. Evolution of Insect Migration and Diapause. Springer, New York.

Rankin M.A., M.L. McAnelly, and J.E. Bodenhamer. 1986. The oogenesis-flight syndrome revisited. Pp. 27-48 in W. Danthanarayana, ed. Insect Flight and Migration. Springer, Berlin.

Rankin M.A. and L.M. Riddiford. 1978. The influence of artificial selection on hemolymph juvenile hormone titers and the timing of reproduction and flight in adult Oncopeltus fasciatus. J Insect Physiol 24:1-38.

Roff D.A. 1986. The evolution of wing dimorphism in insects. Evolution 40:1009-1020.

Roff D.A., G. Stirling, and D.J. Fairbairn. 1997. The evolution of threshold traits: a quantitative genetic analysis of the physiological and life-history correlates of wing dimorphism in the sand cricket. Evolution 51:1910-1919.

Rose M.R., T.J. Nusbaum, and A.K. Chippendale. 1996. Laboratory evolution: the experimental wonderland and the Cheshire cat. Pp. 221-241 in M.R. Rose and G.V. Lauder, eds. Adaptation. Academic Press, San Diego, Calif.

Saunders D.S. 1982. Insect Clocks. Pergamon, Oxford.

Sinervo B. 1999. Mechanistic analysis of natural selection and a refinement of Lack's and Williams's principles. Am Nat 154(suppl.):S26-S42.

Sinervo B., D.B. Miles, D.F. DeNardo, W.A. Frankino, and M. Klukowski. 2000. Testosterone, endurance, Darwinian fitness: proximate bases of the rock-paper-scissors game of alternative male strategies. Horm Behav 38:222-233.

Sokal R.R. and F.J. Rohlf. 1969. Statistical Tables. W. H. Freeman, San Francisco.

1989. Biometry. 2 d ed. W. H. Freeman, San Francisco.

Southwood T.R.E. 1961. A hormonal theory of the mechanism of wing polymorphism in Heteroptera. Proc R Entomol Soc Lond Ser A Gen Entomol 36:63-66.

Stearns S.C. 1992. The Evolution of Life Histories. Oxford University Press, Oxford.

Strambi A., C. Strambi, and M. Cayre. 1997. Hormonal control of reproduction and reproductive behavior in crickets. Arch Insect Biochem Physiol 35:393-404.

Tanaka S. 1994. Endocrine control of ovarian development and flight muscle histolysis in a wing dimorphic cricket, Modicogryllus confirmatus. J Insect Physiol 40:483-490.
Trumbo S.T., D.W. Borst, and G.E. Robinson. 1995. Rapid elevation of juvenile hormone titer during behavioral assessment of the breeding resource by the burying beetle, Nicrophorus orbicollis. J Insect Physiol 41:535-543.

Veazy J.N., C.A.R. Kay, T.J. Walker, and W.H. Whitcomb. 1976. Seasonal abundance, sex ratio, and macroptery of field crickets in northern Florida. Ann Entomol Soc Am 69:374-380.

Walker T.J. 1986. Monitoring the flights of field crickets (Gryllus spp.) and a tachinid fly (Euphasiopteryx ochracea) in north Florida. Fla Entomol 69:678-685.

Walker G.P. and D.L. Denlinger. 1980. Juvenile hormone and moulting hormone titres in diapause- and non-diapause destined flesh flies. J Insect Physiol 26:661-664.

Wigglesworth V.B. 1961. Insect polymorphism-a tentative synthesis. Pages 103-113 in J.S. Kennedy, ed. Insect Polymorphism. Royal Entomological Society, London.

Williams G.C. 1966. Natural selection, the costs of reproduction, and a refinement of Lack's principle. Am Nat 100:687-690.

Wyatt G.R. and K.G. Davey. 1996. Cellular and molecular actions of juvenile hormone. II. Roles of juvenile hormone in adult insects. Adv Insect Physiol 26:1-155.

Zera A.J. 1999. The endocrine genetics of wing polymorphism in Gryllus: critique of recent studies and state of the art. Evolution 53:972-976.

Zera A.J. and J. Bottsford. 2001. The endocrine-genetic basis of life-history variation: relationship between the ecdysteroid titer and morph-specific reproduction in the wingpolymorphic cricket, Gryllus firmus. Evolution (in press).

Zera A.J. and R.F. Denno. 1997. Physiology and ecology of dispersal polymorphism in insects. Annu Rev Entomol 42: 207-231.

Zera A.J. and L.G. Harshman. 2001. The physiology of life history trade-offs. Annu Rev Ecol Syst (in press).

Zera A.J. and Y. Huang. 1999. Evolutionary endocrinology of juvenile hormone esterase: functional relationship with wing polymorphism in the cricket, Gryllus firmus. Evolution 53: $837-847$.

Zera A.J., J. Potts, and K. Kobus. 1998. The physiology of lifehistory trade-offs: experimental analysis of a hormonally induced life-history trade-off in Gryllus assimilis. Am Nat 152: $7-23$.

Zera A.J. and M.A. Rankin. 1989. Wing dimorphism in Gryllus rubens: genetic basis of morph determination and fertility differences between morphs. Oecologia 80:249-255.

Zera A.J., I. Sall, and K. Grudzinski. 1997. Flight-muscle polymorphism in the cricket Gryllus firmus: muscle characteristics and their influence on the evolution of flightlessness. Physiol Zool 70:519-529.

Zera A.J., J. Sall, and K. Otto. 1999. Biochemical aspects of flight and flightlessness in Gryllus: flight fuels, enzyme activities and electrophoretic profiles of flight muscles from flight-capable and flightless morphs. J Insect Physiol 45: 275-285. 
Zera A.J., C. Strambi, K.C. Tiebel, A. Strambi, and M.A. Rankin. Zera A.J. and K.C. Tiebel. 1989. Differences in juvenile hormone 1989. Juvenile hormone and ecdysteroid titers during critical periods of wing morph determination in Gryllus rubens. J Insect Physiol 35:501-511. esterase activity between presumptive macropterous and brachypterous Gryllus rubens. implications for the hormonal control of wing polymorphism. J Insect Physiol 35:7-17. 